\title{
Mechanisms of Carbon Monoxide and Methanol Oxidation at Single-crystal Electrodes
}

\author{
S. C. S. Lai · N. P. Lebedeva - T. H. M. Housmans • \\ M. T. M. Koper
}

Published online: 12 October 2007

(C) Springer Science+Business Media, LLC 2007

\begin{abstract}
The electrochemical oxidation of carbon monoxide and methanol on single-crystal noble metal electrodes has been studied using cyclic voltammetry, chronoamperometry, in situ FTIR spectroscopy, online electrochemical mass spectrometry, and theoretical methods. The oxidation of $\mathrm{CO}$ was found to be enhanced by steps and defects. Furthermore, the surface diffusion rate was found to have a significant influence on the kinetics of the oxidation process: for high diffusion rates, such as the oxidation of $\mathrm{CO}$ on platinum, the kinetics can be described by a mean field model, while for low diffusion rates, such as $\mathrm{CO}$ oxidation on rhodium in sulfuric acid, a nucleationand-growth model was found to be more suitable. Voltammetric and mass spectrometric measurements on the oxidation of methanol on platinum indicate that steps enhance the overall reaction rate. In general, the selectivity towards the direct oxidation pathway through soluble intermediates was found to be higher in the absence of strongly adsorbing anions. In both perchloric and sulfuric acid, this selectivity was also found to increase with increasing step density. In sulfuric acid, $\mathrm{Pt}(111)$ shows the highest relative contribution for the direct pathway of all
\end{abstract}

S. C. S. Lai · M. T. M. Koper ( $\square)$

Leiden Institute of Chemistry, Leiden University, Einsteinweg

55, P.O. Box 9502, 2300 RA Leiden, The Netherlands

e-mail: m.koper@chem.leidenuniv.nl

N. P. Lebedeva

Energy Research Centre of The Netherlands (ECN),

Westerduinweg 3, P.O. Box 1, 1755 LE Petten, The Netherlands

e-mail: lebedeva@ecn.nl

T. H. M. Housmans

Sabic Europe, Urmonderbaan 22, P.O. Box 319, 6160 AH

Geleen, The Netherlands

e-mail: Tom.Housmans@Sabic-Europe.com surfaces studied in that electrolyte. Based on these results, a detailed reaction scheme for the electrochemical oxidation of methanol is presented.

Keywords Carbon monoxide - Methanol . Electrochemical oxidation - Platinum - Rhodium . Single-crystal electrodes

\section{Introduction}

Understanding the molecular mechanisms of catalytic reactions in fuel cells is of crucial importance in achieving the ultimate goal of fundamental catalysis research: a rational design of new catalysts. Establishing the fundamental molecular principles of catalytic reactions requires experimental and theoretical studies on well-defined and well-characterized catalytic surfaces, under well-defined reaction conditions. In the past few years, we have adopted this "surface science" approach to fuel cell catalysis in order to gain more insight into the basic mechanisms of the electrooxidation of carbon monoxide and methanol at single-crystal noble metal electrodes. Such insight should eventually aid in improving the $\mathrm{CO}$ tolerance of low-temperature fuel cell anodes, and developing better methanol oxidation catalysts for the direct methanol fuel cell.

One key issue in fundamental heterogeneous catalysis studies is the identification of the active site. We have tackled this particular problem by working with a series of stepped single-crystal electrodes. Studies at low-index single-crystal surfaces allow one to relate reactivity to the surface structure, and stepped single-crystal surfaces provide a convenient way to systematically assess the role of steps and defects. 
In this paper, we will summarize several previously performed studies on the electrochemical oxidation of carbon monoxide on stepped single-crystal platinum and rhodium electrodes and the electrooxidation of methanol on single-crystal platinum electrodes, employing a combination of electrochemical and theoretical techniques. Based on the findings, models for both the electrochemical oxidation of $\mathrm{CO}$ and the oxidation of methanol are proposed.

\section{CO Electrooxidation on Pt}

The electrochemical oxidation of $\mathrm{CO}$ on platinum is certainly among the most extensively studied reactions in electrocatalysis over the past decades, since it is of both fundamental and practical interest. The achievements until 1990 in the understanding of this reaction have been reviewed by Beden et al. [1].

The "reactant-pair" mechanism for the electrochemical oxidation of adsorbed $\mathrm{CO}$ in acidic solutions, originally proposed by Gilman [2], is now generally accepted. This mechanism assumes a Langmuir-Hinshelwood type reaction between carbon monoxide and a surface oxygencontaining species, adsorbed on adjacent sites, to form $\mathrm{CO}_{2}$. The oxygen-containing species results from the oxidation of water at the electrode surface and is usually supposed to be $\mathrm{OH}_{\mathrm{ads}}$, although the exact nature of this species is still elusive. Since the potential dependence of the reaction was found to be about $70-80 \mathrm{mV} / \mathrm{dec}$, the presence of a slow chemical step in the reaction scheme was suggested in a number of publications [3, 4]. The overall reaction scheme is:

$$
\begin{aligned}
& \mathrm{H}_{2} \mathrm{O}+* \rightleftarrows \mathrm{OH}_{\mathrm{ads}}+\mathrm{H}^{+}+\mathrm{e}^{-} \\
& \mathrm{CO}_{\mathrm{ads}}+\mathrm{OH}_{\mathrm{ads}} \rightarrow \mathrm{COOH}_{\mathrm{ads}} \quad \text { (rds) } \\
& \mathrm{COOH}_{\mathrm{ads}} \rightarrow \mathrm{CO}_{2}+\mathrm{H}^{+}+\mathrm{e}^{-}+2 *
\end{aligned}
$$

where * denotes a free surface site, reactions (1) and (3) are fast and reaction (2) is the rate determining step (at least at the relatively high overpotentials studied in this work). The rate of reaction (2) depends on the CO surface diffusion rate, which in turn is determined by the spatial distribution of the reactants on the surface of the reactants. Analytical expressions for the overall reaction rate can be derived for two limiting cases known as the "mean field approximation" and the "nucleation-and-growth model". One of the assumptions of the mean field approximation is that reactants are perfectly mixed on the surface and the reaction rate is proportional to the average coverages of the reaction partners [5]. This assumption is reasonable if the surface diffusion is much faster than the reaction itself. In the nucleation-and-growth model, the reacting species are considered immobile. In the case of a surface pre-dosed with a saturated adlayer of $\mathrm{CO}$, the adsorption of $\mathrm{OH}$ proceeds via "nucleation" at certain places, for instance at defects in the $\mathrm{CO}$ adlayer. The reaction takes place only at the interface between the two reacting phases, leading to the formation and growth of islands. For diffusion rates comparable with the reaction rate, a full numerical solution of the kinetic equations is required. In this case, one either resorts to so-called Dynamic Monte Carlo simulations [6, 7] or to a differential-equation approach involving a more advanced approximation than the mean field model [8].

In order to systematically investigate the mechanism and the kinetics of the electrooxidation of $\mathrm{CO}$ on platinum electrodes, voltammetric [9] and chronoamperometric studies $[10,11]$ were performed on a number $\operatorname{Pt}[n(111) \times$ (111)] vicinal surfaces. For an fcc metal like platinum, the $[n(111) \times(111)]$ surfaces are composed of terraces of (111) orientation, which are $(n-1)$ atoms wide, separated by monoatomic steps of (110) orientation. The surfaces studied were $\operatorname{Pt}(151514)$ with $n=30, \operatorname{Pt}(554)$ with $n=10, \operatorname{Pt}(553)$ with $n=5$ and the limiting cases $\operatorname{Pt}(111)$ and $\operatorname{Pt}(110)$. In the voltammetric study [9], a pronounced catalyzing effect of steps was observed in the $\mathrm{CO}$ adlayer oxidation for the entire range of $\mathrm{CO}$ coverages as well as for the oxidation of dissolved CO. Figure 1 illustrates how a higher step density lowers the overpotential for $\mathrm{CO}$ adlayer oxidation, the difference between peak potentials for $\mathrm{Pt}(553)$ and $\mathrm{Pt}(111)$ being as high as $0.17 \mathrm{~V}$. This effect has been explained by the preferential formation of oxygen-containing species at the step sites compared to the terrace sites, even when electrode surface is pre-dosed with $\mathrm{CO}[9]$.

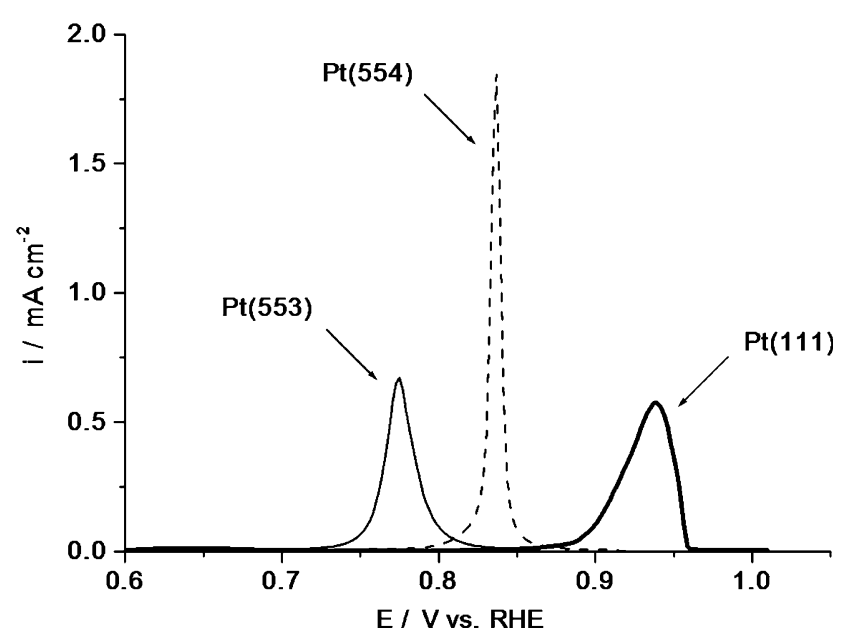

Fig. 1 Oxidation of saturated CO adlayers on $\mathrm{Pt}(553)$ (thin solid line), $\operatorname{Pt}(554)$ (dashed line), and $\operatorname{Pt}(111)$ (thick solid line), sweep rate $50 \mathrm{mV} / \mathrm{s}, T=25^{\circ} \mathrm{C}$ [9] 
For a quantitative study of the reaction kinetics of $\mathrm{CO}$ adlayer electrooxidation on $\operatorname{Pt}[n(111) \times(111)]$ chronoamperometry or potential-step experiments were employed $[10,11]$. Characteristic current transients for the oxidation of the saturated adlayer of $\mathrm{CO}$ are shown in Fig. 2. All the transients have a similar shape: after charging of the double layer (a high current at short times) there is a current plateau followed by a main peak. The current in the plateau region is found to depend on the step density [10]. The major enhancement of the rate of the $\mathrm{CO}$ adlayer oxidation in the plateau region is observed when passing from $\mathrm{Pt}(111)$ to $\operatorname{Pt}(1515$ 14), the plateau current increasing by one order of magnitude. Further increase of the step density does not lead to a significant rise of the current in the plateau region, emphasizing the extraordinary role of a small amount of defect sites in the oxidation initiation step [10].

The mechanism of the reaction initiation has been discussed in several papers [10-14]. The dependence of the plateau current on the defect density makes an Eley-Rideal type of reaction initiation proposed by Bergelin et al. [12] rather unlikely and points towards a Langmuir-Hinshelwood mechanism with no effective freeing of sites for $\mathrm{OH}$ adsorption as the first few $\mathrm{CO}$ molecules are oxidized, due to the relaxation of the $\mathrm{CO}$ adlayer upon removal of these first CO molecules [10, 11, 13, 14].

Once the reaction is initiated, the oxidation of $\mathrm{CO}$ proceeds via a Langmuir-Hinshelwood mechanism as can be concluded from the peaked shape of the current transients. The promoting effect of steps on the $\mathrm{CO}$ oxidation rate is obvious: the higher the step density the faster the reaction. For example, it takes approximately $300 \mathrm{~s}$ to complete oxidation of a saturated $\mathrm{CO}$ adlayer on $\operatorname{Pt}(111)$ at $0.73 \mathrm{~V}$, while on $\operatorname{Pt}(110)$ only ca. $5 \mathrm{~s}$ are required even though the saturation coverage of $\mathrm{CO}$ on $\mathrm{Pt}(110)$ is higher (Fig. 1). These results are in line with previous observations of enhanced activity towards $\mathrm{CO}$ oxidation of surfaces with an increased defect density [3, 6, 15].

The shape of the transients changes slightly with the density of steps. For the surfaces with low step density, $\operatorname{Pt}(111), \operatorname{Pt}(151514)$, and $\operatorname{Pt}(554)$, the main peak is symmetric, while for $\operatorname{Pt}(553)$ and especially $\operatorname{Pt}(110)$, a tailing on the descending part of the transient is observed (Fig. 2). Despite this variation of the transient shape, the main peak can be fitted satisfactorily by a mean field model in the entire range of step potentials and for all $\operatorname{Pt}[n(111) \times$ (111)] surfaces (examples are shown in Fig. 3). For more details on the fitting procedure, the reader is referred to the original paper [10]. The nucleation-and-growth model gives a fit of the transients, which is significantly inferior to that of the mean field model [10, 11]. Instantaneous nucleation-and-growth can be ruled out since the ascending part of the transients is clearly not linear, and progressive nucleation-and-growth results in noticeably broader transients (dashed lines in Fig. 3). Neither the mean field model nor the nucleation-and-growth model are able to reproduce the slight tailing on the descending part of the transients for electrodes with high step density $(\operatorname{Pt}(553)$ and $\mathrm{Pt}(110)$ ) exactly. To investigate whether the tailing of the current transients for surfaces with a high step density could be related to a slow diffusion of $\mathrm{CO}$ on the terraces, the reaction kinetics were simulated by solving the kinetic differential equations numerically [10]. The results of the simulation showed that the tailing is likely related to the slow oxidation of the $\mathrm{CO}$ molecules that remain on the steps after the oxidative removal of $\mathrm{CO}$ from terraces and not to slow diffusion of the $\mathrm{CO}$ molecules. Since the fraction of CO molecules on steps is less than $20 \%$ even for $\operatorname{Pt}(553)$, we believe that the observed tailing does not undermine the mean field model. Therefore, the apparent rate constants for reaction (2) for all $\mathrm{Pt}[n(111) \times(111)]$ electrodes and all final potentials were obtained by fitting the experimental transients with a mean field model. The determined apparent reaction constants lie in the range from $10^{-2}$ to $10^{2} \mathrm{~s}^{-1}$ depending on the potential and step density.

From the evaluation of the apparent reaction rate constants it was observed that for surfaces with $n>5$, the apparent rate constant increases linearly with step density at a given potential, indicating that steps indeed are the active sites. The potential dependence of the apparent rate constants is essentially independent of the step density: $75 \pm 3 \mathrm{mV} / \mathrm{dec}$ for $\mathrm{Pt}(111), 85 \pm 3 \mathrm{mV} / \mathrm{dec}$ for $\mathrm{Pt}(1515$ 14), $78 \pm 4 \mathrm{mV} / \mathrm{dec}$ for $\operatorname{Pt}(554), \quad 97 \pm 4 \mathrm{mV} / \mathrm{dec}$ for $\mathrm{Pt}(553)$, and $81 \pm 3 \mathrm{mV} / \mathrm{dec}$ for $\mathrm{Pt}(110)$. Similar Tafel slopes of $60-80 \mathrm{mV} / \mathrm{dec}$ were found in a number of the earlier studies $[12,16]$. The indifference of the Tafel slope to the surface structure could suggest that $\mathrm{CO}$ oxidation follows the same mechanism on all surfaces studied. The value of the Tafel slope being relatively close to $60 \mathrm{mV} /$ dec can be interpreted in terms of a slow chemical step (2) in the reaction mechanism (1)-(3).

The mobility of chemisorbed $\mathrm{CO}$ under electrochemical conditions and hence the appropriate kinetic model for $\mathrm{CO}$ oxidation has been a central issue of many experimental [3, $12,13,17]$ and theoretical studies [6, 18]. Since the kinetics of the reaction in the region of the peak is well described by a mean field approximation (Fig. 3), it was concluded that $\mathrm{CO}$ must be very mobile on the (111) terraces of all $\mathrm{Pt}[n(111) \times(111)]$ surfaces. This is in agreement with the fast diffusion of CO on platinum (111) terraces under UHV conditions with a typical hopping rate in the order of $10^{5} \mathrm{~s}^{-1}$ at $195 \mathrm{~K}$ and low CO coverage [1921] and $10^{7} \mathrm{~s}^{-1}$ at $300 \mathrm{~K}$ and $\mathrm{CO}$ coverage of $0.67 \mathrm{M}$ [22]. From reviewing over 500 systems Seebauer et al. concluded an apparent insensitivity of diffusional parameters to the presence of an aqueous ambient [23], which suggests 

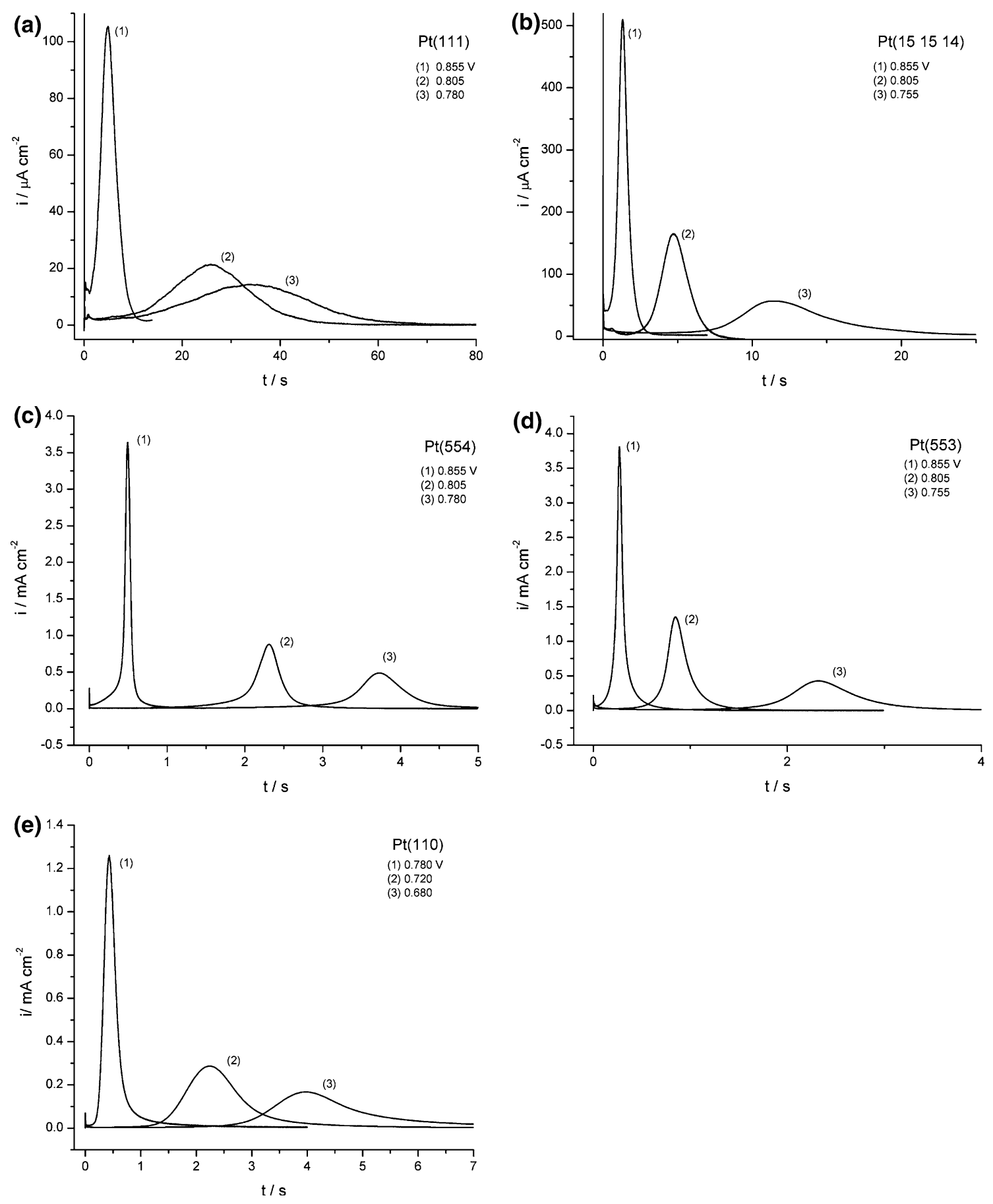

Fig. 2 Current-time transients of the oxidation of saturated CO adlayers on (a) $\operatorname{Pt}(111),(\mathbf{b}) \operatorname{Pt}(1515$ 14), (c) $\operatorname{Pt}(554),(\mathbf{d}) \operatorname{Pt}(553)$, and (e) $\mathrm{Pt}(110)$. Final potentials are indicated in the figure [10]

that a high hopping rate of $\mathrm{CO}$ should be expected under electrochemical conditions as well. Having determined the apparent rate constant $k$ of $\mathrm{CO}$ oxidation and taking into account the requirements for $k / D$ for the mean field approximation to be valid, we have estimated the diffusion coefficient $D$ for CO on (111) terraces to be higher than $10^{-}$ ${ }^{11} \mathrm{~cm}^{2} / \mathrm{s}$ [10]. This, in turn, would correspond to the hopping rate of $10^{5} \mathrm{~s}^{-1}$, which is, taking into account the very approximate character of the present estimation, in good agreement with the hopping rate of $\mathrm{CO}$ on (111) terraces in UHV.

To acquire more molecular level knowledge on the reaction mechanism, in situ infrared reflection-absorption spectroscopy (IRRAS) was employed to study adsorption as well as oxidation of the $\mathrm{CO}$ adlayers on $\mathrm{Pt}$ stepped surfaces with (110) and (100) steps [24]. One of the 

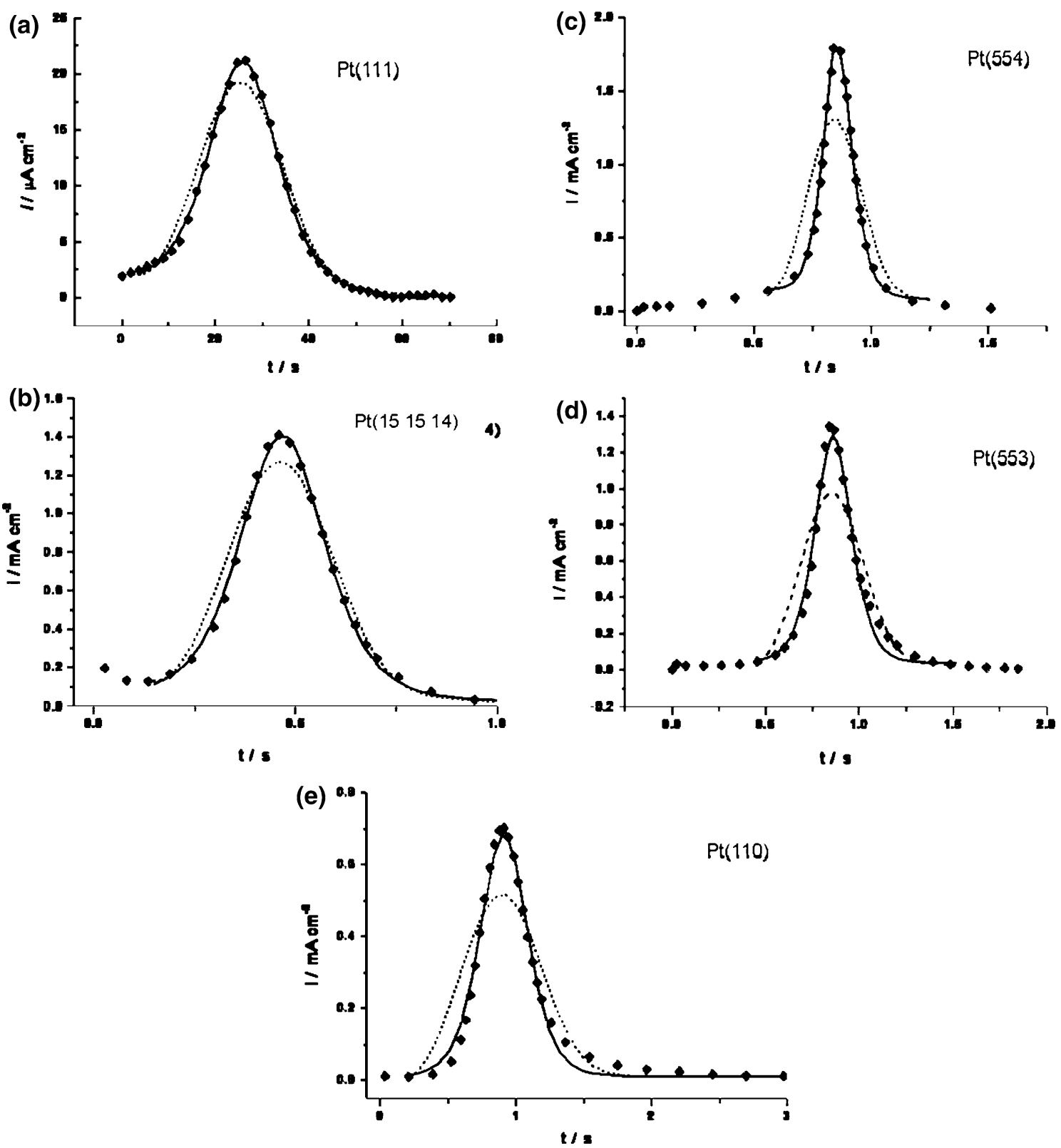

Fig. 3 Current-time transients for saturated $\mathrm{CO}$ adlayer oxidation on (a) $\operatorname{Pt}(111)$ at final potential $E_{\mathrm{f}}=0.805 \mathrm{~V}$, (b) $\operatorname{Pt}(151514)$ at $E_{\mathrm{f}}=0.88 \mathrm{~V}$, (c) $\operatorname{Pt}(554) E_{\mathrm{f}}=0.83 \mathrm{~V}$, , (d) $\operatorname{Pt}(553) E_{\mathrm{f}}=0.805 \mathrm{~V}$, and (e) $\operatorname{Pt}(110) E_{\mathrm{f}}=0.755 \mathrm{~V}$. The experimental data (diamonds) are fitted

advantages of IRRAS is its ability to sensitively discriminate between adsorbates on different adsorption sites, i.e., steps and terraces, making it a powerful technique for catalyst surface characterization and in situ investigation of the nature and structure of the active sites [25-27]. It was found that $\mathrm{CO}$ adsorbed on terraces is more reactive than $\mathrm{CO}$ adsorbed on steps [24]. Furthermore, by comparing the in situ infrared spectra of $\mathrm{CO}$ oxidation on $\mathrm{Pt}(322)$, and $\mathrm{Pt}(332)$, it was concluded the oxidation reaction takes place in the inner corner of the steps, where $\mathrm{OH}_{\mathrm{ads}}$ reacts with $\mathrm{CO}$ adsorbed in the terraces, leaving $\mathrm{CO}$ adsorbed on the by a mean field approximation (solid line) and a progressive nucleation-and-growth model (dashed line). Only a few experimental data points are depicted for the sake of clarity [10]

steps behind. The $\mathrm{CO}$ molecules adsorbed on the steps oxidize slowly through conversion into "terrace" $\mathrm{CO}$ and subsequent fast diffusion to the step sites. This mechanism is similar to that suggested for $\mathrm{CO}$ oxidation on stepped $\mathrm{Pt}$ in UHV [28].

\section{CO Electrooxidation on $\mathrm{Rh}$}

Although rhodium is well known to be active in the oxidation of $\mathrm{CO}$ in automobile catalysis and has been 
investigated extensively under UHV and gas-phase conditions, the electrooxidation of $\mathrm{CO}$ on rhodium catalysts has received much less attention. In UHV experiments, the oxidation of $\mathrm{CO}$ by $\mathrm{O}_{2}$ was found to be a structure sensitive Langmuir-Hinshelwood type mechanism [29].

To systematically investigate the mechanism and the kinetics of the electrochemical oxidation of $\mathrm{CO}$ on rhodium electrodes, voltammetric [30] and chronoamperometric [31] studies were performed on a number of $\operatorname{Rh}[n(111) \times$ (111)] single-crystal electrodes $(\mathrm{Rh}(331), \mathrm{Rh}(553)$, $\operatorname{Rh}(554)$, and $\operatorname{Rh}(111)$, with $n=3, n=5, n=10$, and $n=200-500$, respectively), which, like $\operatorname{Pt}[n(111) \times(111)]$ are composed of terraces of (111) orientation of $(n-1)$ atoms wide separated by monoatomic steps of (110) orentiation. A significant complication in studying the oxidation of $\mathrm{CO}$ on $\mathrm{Rh}$ is the fact that the $\mathrm{CO}$ electrooxidation potential overlaps with the surface oxidation potential, causing surface disordering to occur simultaneously with the oxidation of CO. Therefore, two types of electrodes were investigated: "ordered" electrodes, which were meticulously kept below the surface oxidation potential during the recording of the blank cyclic voltammograms, and "disordered" electrodes, which are obtained by cycling the blank CV's up to $0.85 \mathrm{~V}$ (versus RHE), well into the surface oxidation region of the investigated $\mathrm{Rh}$ surfaces, until a steady state blank voltammogram was reached. Another problem is incomplete oxidative stripping of $\mathrm{CO}$ adlayers on Rh surfaces: several scans are usually required to completely strip the $\mathrm{CO}$ adlayer, making it more difficult to draw quantitative conclusions from voltammetric measurements.

The blank cyclic voltammograms show a distinct increase in the reversibility in the hydrogen/(bi)sulfate region $(0.05-0.20 \mathrm{~V})$ with increasing step density [30]. Also, the total integrated charge under the hydrogen/ (bi)sulfate peaks was found to decrease with increasing step density, indicating that (bi)sulfate adsorption preferably takes place on the terraces rather than on the steps and defects. This negative correlation between (bi)sulfate adsorption and the number of steps was also observed in $\mathrm{CO}$ displacement experiments, although a quantitative discrepancy still remains.

CO stripping voltammograms of the "ordered" electrodes in $\mathrm{H}_{2} \mathrm{SO}_{4}$ (Fig. 4a) show a small shoulder between 0.6 and $0.7 \mathrm{~V}$ (versus RHE) followed by a single asymmetrical oxidation peak with a maximum around $0.73 \mathrm{~V}$ (versus RHE). The number of scans for full oxidative CO stripping varied from 2 for $\mathrm{Rh}(331)$ to 30 for $\mathrm{Rh}(111)$. The charge under the shoulder was found to be linearly correlated with the step density, leading to the conclusion that the steps and defects are the active sites. The presence of the shoulder can be explained by assuming that $\mathrm{CO}$ reacts first at the steps at low potential. The tailing of the asymmetric main oxidation peaks suggests a low $\mathrm{CO}$ surface mobility. The stripping voltammograms of the "disordered" electrodes show notably different features: there is only one oxidation feature, at lower potentials and with a less pronounced tailing compared to their "ordered" counterparts. In addition, the number of scans needed to completely strip the $\mathrm{CO}$ adlayer is roughly halved, all of which indicating a large increase in (randomly distributed) defects for the "disordered" electrodes.

The current-time transients of $\mathrm{CO}$ adlayer oxidation on the $\operatorname{Rh}[n(111) \times(111)]$ single-crystal electrodes were recorded at a number of step potentials, varying between 0.590 and $0.655 \mathrm{~V}$ (versus RHE) (a few examples are shown in Fig. 5). All transients show a current plateau directly after charging of the double layer, followed by a pre-peak and a main oxidation peak. Similar to the oxidation of $\mathrm{CO}$ on $\mathrm{Pt}$, the current plateau region shows a ("quasi"-)zeroth reaction order with respect to $\mathrm{CO}$ coverage. Moreover, the introduction of a small number of steps (as observed by going from $\mathrm{Rh}(111)$ to $\mathrm{Rh}(554)$ ), results in a significant increase in the plateau current, while a further increase in step density has a much smaller effect on the current density. In contrast to the Tafel slopes of $\sim 80 \mathrm{mV} /$ dec found for Pt electrodes [10], the Tafel slopes for the plateau currents on $\mathrm{Rh}$ were found to be between 40 and $50 \mathrm{mV} / \mathrm{dec}$, suggesting the second electron transfer (reaction (3)) to be rate determining for the initiation of the oxidation of $\mathrm{CO}$ on $\mathrm{Rh}$.

The position of the pre-peak was found to be relatively structure insensitive, while the charge associated with it increases with step density, indicating that the process associated with this peak is restricted to the steps. Therefore, it is likely that this peak is caused by the adsorption of oxygenated species at a step site and subsequent reaction with a neighboring $\mathrm{CO}$ molecule. Contrary to the pre-peak, the main oxidation peak depends strongly on the structure of the surface: for surfaces with a low step density, such as $\mathrm{Rh}(111)$ and $\mathrm{Rh}(554)$, the main oxidation peak is asymmetrical in shape and characterized by a fast current increase followed by a slow current decay. On $\mathrm{Rh}(553)$ the current increase is slower and the decay faster than on $\mathrm{Rh}(111)$ and $\mathrm{Rh}(554)$. A further increase in step density to $\mathrm{Rh}(331)$ leads to nearly symmetrical peaks. The strong asymmetry of the peaks on the surfaces with a low step density suggests that on rhodium in sulfuric acid the oxidation of $\mathrm{CO}$ is better described by a nucleation-andgrowth model than by a mean field approximation, indicating a slow diffusion of $\mathrm{CO}$ towards the active sites. As the terrace width is decreased, the influence of diffusion decreases, resulting in nearly symmetrical peaks for $\mathrm{Rh}(331)$, the surface with the highest step density in this investigation. In comparison with $\mathrm{Pt}$, the $\mathrm{CO}$ oxidation reaction on Rh occurs at lower potentials. The Tafel slopes 
Fig. $4 \mathrm{CO}$ adlayer oxidation voltammograms on "ordered" $\mathrm{Rh}(111)$ (thin solid line), $\mathrm{Rh}(554)$ (dashed line), $\mathrm{Rh}(553)$ (dotted line), and $\mathrm{Rh}(331)$ (thick solid line) electrodes in (a) $\mathrm{H}_{2} \mathrm{SO}_{4}$ and (b) $\mathrm{HClO}_{4}$. The inset in (a) shows a zoom of the $\mathrm{CO}$ oxidation on $\mathrm{Rh}(111)$. The scan rates were $20 \mathrm{mV} / \mathrm{s}[30,34]$
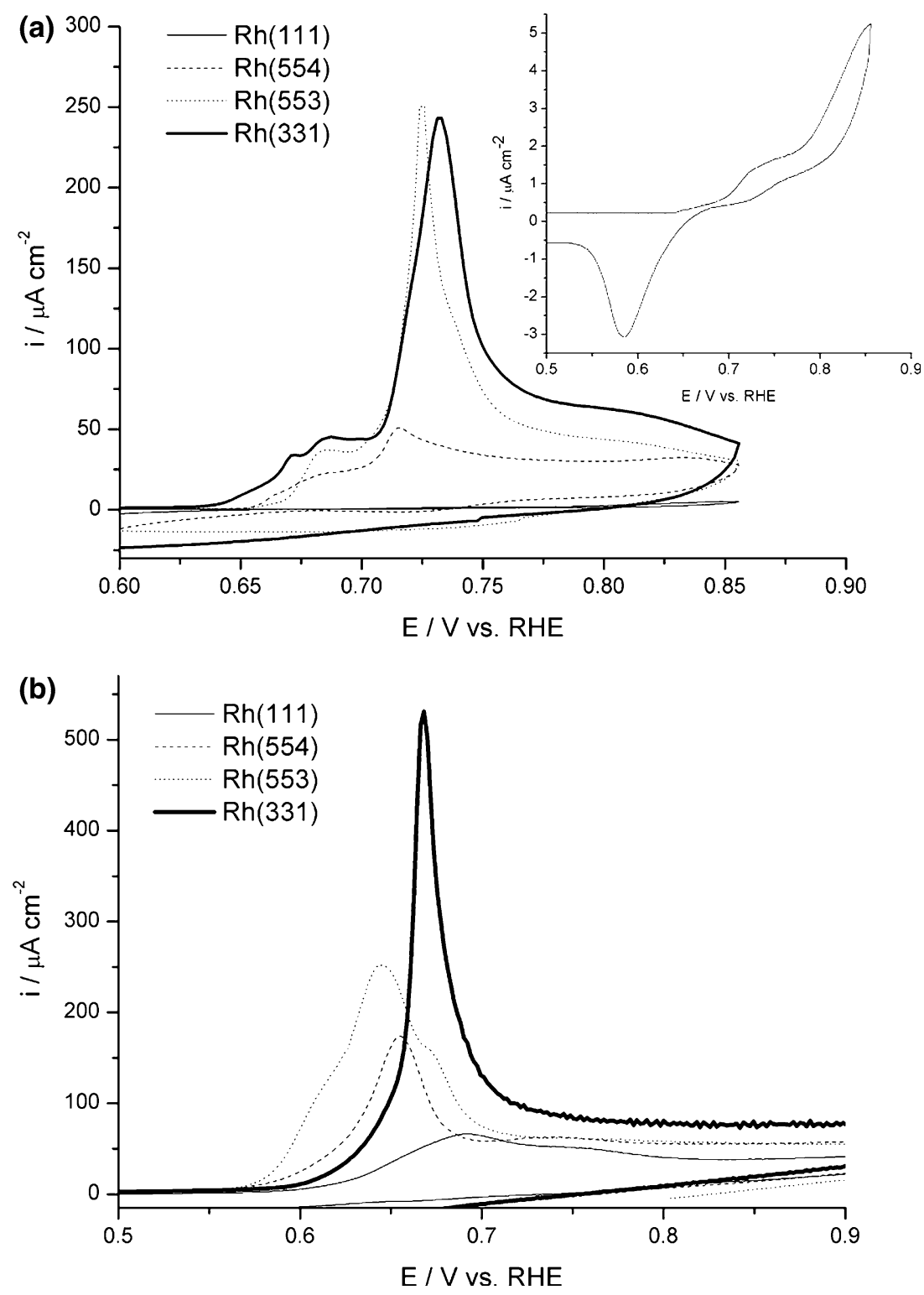

obtained from the oxidation peak were 49-61 mV/dec, close the values for $\mathrm{Pt}$ and close to $60 \mathrm{mV} / \mathrm{dec}$, indicating the same rate determining chemical step on both $\mathrm{Pt}$ and $\mathrm{Rh}$ electrodes. Due to the structure sensitivity of the main peak, as well as the separation from the pre-peak, the main oxidation peak cannot be due to the oxidation at the step sites: if the step sites were the only active sites for the oxidation of $\mathrm{CO}$, a low $\mathrm{CO}$ mobility would lead to a single oxidation peak with a pronounced tailing rather than a twopeaked structure. Since the potential of the electrooxidation of $\mathrm{CO}$ coincides with the surface oxidation potential of $\mathrm{Rh}$, $\mathrm{OH}$ adsorption is likely to occur on the terraces during the potential-step measurements. Therefore, the main oxidation peak is ascribed to $\mathrm{CO}$ oxidation on the terraces in combination with its slow surface diffusion.
The voltammetric and chronoamperometric results indicate a slow surface diffusion of $\mathrm{CO}$ on rhodium surfaces in a sulfate medium. In contrast, under UHV conditions the diffusion rate of $\mathrm{CO}$ on rhodium surfaces is found to be high $[32,33]$. To investigate whether the discrepancy between the electrochemical results and the results from UHV may be attributed to the strong anion adsorption of (bi)sulfate, similar measurements were performed in a perchloric acid electrolyte [34]. The voltammograms of $\mathrm{CO}$ adlayer oxidation on $\mathrm{Rh}[n(111) \times$ (111)] single-crystal electrodes in perchloric acid are shown in Fig. 4b. The voltammograms differ in a number of ways from those recorded in sulfuric acid: first, similar to $\mathrm{CO}$ stripping on $\mathrm{Pt}[n(111) \times(111)]$ electrodes [35], the onset of the oxidation peaks lie at lower potentials in 

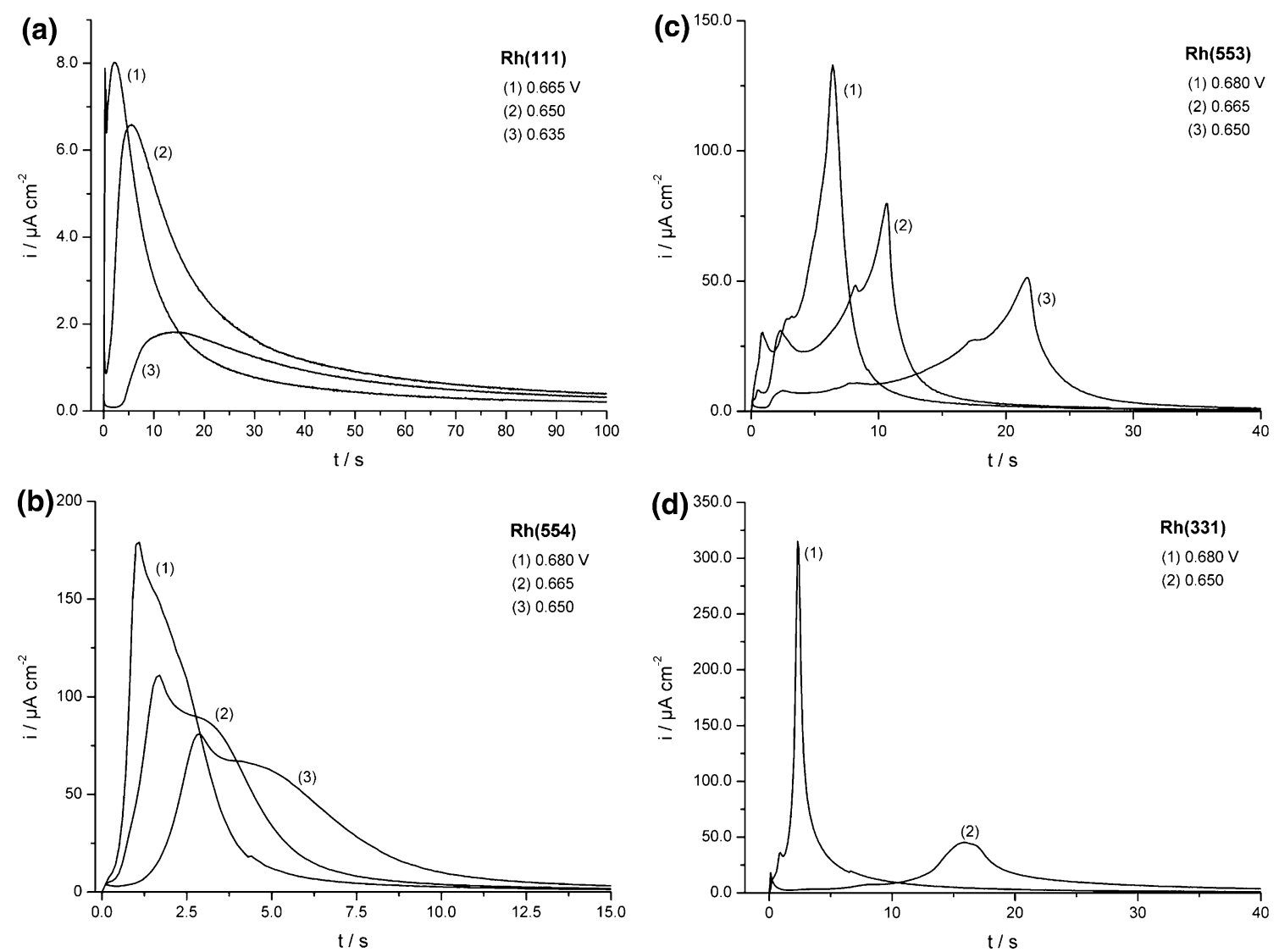

Fig. 5 Current-time transients of the stripping oxidation of saturated CO adlayers on (a) $\operatorname{Rh}(111),(\mathbf{b}) \operatorname{Rh}(554),(\mathbf{c}) \operatorname{Rh}(553)$, and (d) $\operatorname{Rh}(331)$ in $0.5 \mathrm{M} \mathrm{H}_{2} \mathrm{SO}_{4}$. All final potentials are listed in the figure [31]

perchloric than in sulfuric acid media. The faster oxidation is also observed in the number of scans needed for complete adlayer stripping, which requires only up to three cycles in perchloric media for the surfaces studied. Moreover, in contrast to sulfuric acid, the voltammetric stripping peak in perchloric acid shifts to lower potentials with increasing step density (with the exception of $\operatorname{Pt}(331)$ ), a feature which is readily explained by a higher $\mathrm{CO}$ surface diffusion in the latter media. Notable is also the disappearance of the shoulder prior to the main oxidation peak and the higher symmetry of the main peak (i.e. no tailing is observed), suggesting that $\mathrm{CO}$ adlayer oxidation in perchloric acid is not limited by CO surface diffusion as it is in sulfuric acid. This was also observed in the chronoamperometric measurements of $\mathrm{CO}$ adlayer oxidation in perchloric media: all current-time transients recorded in perchloric acid (Fig. 6) show single oxidation peaks which are shifted towards shorter times and have higher maximum current densities compared to the transients recorded in sulfuric acid media, again indicating a faster oxidation which is not limited by surface diffusion.

Based on the aforementioned observations, the following model for the reaction mechanism of $\mathrm{CO}$ oxidation on rhodium surfaces was proposed: similar to $\mathrm{CO}$ oxidation on $\mathrm{Pt}$, the reaction is initiated in the trough of the steps, where adsorbed oxygen-containing species react with the neighboring $\mathrm{CO}$ molecules. Then, depending on the anion adsorption strength, there are two possibilities. Strongly bound anions, such as (bi)sulfate, restrict the diffusion of $\mathrm{CO}$ to the now freed active sites by blocking empty surface sites, thereby inhibiting the $\mathrm{CO}$ oxidation reaction. The reaction can proceed at potentials at which water dissociation on terrace sites is possible. The formed $\mathrm{OH}_{\text {ads }}$ species displace the adsorbed (bi)sulfate anions on the terraces, leading to the oxidation of $\mathrm{CO}$ on the terraces. The difference in potential at which $\mathrm{OH}_{\text {ads }}$ species are formed on steps and on terraces leads to the double peaked structure of the CO stripping transients. In media with more weakly bound anions, such as perchlorate anions, the mechanism is similar to $\mathrm{CO}$ oxidation on platinum surfaces: after the initiation, the reaction proceeds through fast diffusion of $\mathrm{CO}$ towards the empty sites near the steps, becoming available for oxidation by the replenished $\mathrm{OH}_{\mathrm{ad}}$ species, leading to kinetics being best described by a mean field model. Therefore, this model implies that specific anion adsorption can affect the dynamics of the $\mathrm{CO}$ 

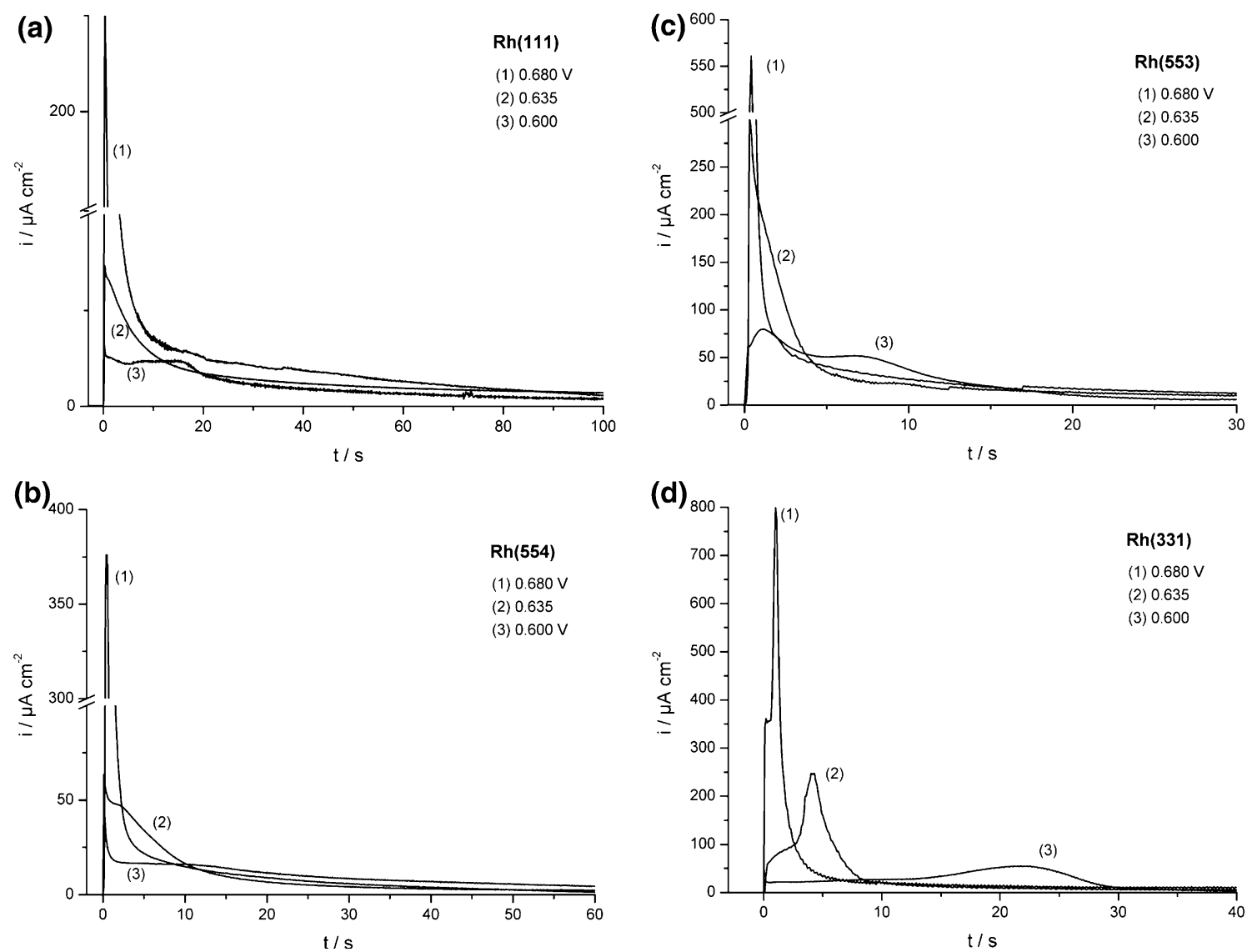

Fig. 6 Current-time transients of the stripping oxidation of saturated CO adlayers on $(\mathbf{a}) \operatorname{Rh}(111),(\mathbf{b}) \operatorname{Rh}(554),(\mathbf{c}) \operatorname{Rh}(553)$, and $(\mathbf{d}) \operatorname{Rh}(331)$ in $0.5 \mathrm{M} \mathrm{HClO}_{4}$. All final potentials are listed in the figure [34]

electrooxidation reaction, shifting the mechanism from a mean field approximation to a nucleation-and-growth model with increasing anion adsorption strength. Dynamic Monte Carlo simulations with varying diffusion rates were found to be in agreement with this model [36].

\section{Methanol Electrooxidation on Pt}

The decomposition of methanol on platinum produces surface poisoning species, inhibiting the catalytic activity. The main poisoning species has been identified in many studies to be surface-bonded carbon monoxide [37, 38]. One of the early mechanistic issues has been whether the adsorbed carbon monoxide is an intermediate in the complete oxidation to $\mathrm{CO}_{2}$ or a byproduct in an unwanted parallel reaction. Currently, it is generally accepted that the electrochemical oxidation of methanol proceeds via a dual path mechanism, in which the decomposition of methanol to form $\mathrm{CO}_{\mathrm{ads}}$ is identified as the indirect pathway, while the reaction via soluble intermediates is often referred to as the direct pathway [37]. Based on ab initio density functional theory (DFT) calculations, Cao et al. suggested that the dual pathway is already initiated at the first methanol dehydrogenation step [39]: $\mathrm{C}-\mathrm{H}$ bond cleavage leads to an adsorbed hydroxymethyl $\mathrm{CH}_{2} \mathrm{OH}$ intermediate, which is further dehydrogenated to $\mathrm{CO}_{\text {ads }}$, while $\mathrm{O}-\mathrm{H}$ bond cleavage leads to adsorbed methoxy, $\mathrm{CH}_{3} \mathrm{O}$, which binds to $\mathrm{Pt}$ via the oxygen. The adsorbed methoxy intermediate is further dehydrogenated to $\mathrm{H}_{2} \mathrm{CO}_{\text {ads }}$, which can subsequently desorb as formaldehyde.

To investigate the structure sensitivity of the methanol oxidation dual pathway, an online electrochemical mass spectrometry (OLEMS) and voltammetric study has been performed on the electrochemical oxidation of methanol on the basal planes of $\mathrm{Pt}$ and several stepped $\operatorname{Pt}[n(111) \times$ (111)] surfaces in both sulfuric and perchloric acid [40]. The surfaces studied include $\operatorname{Pt}(100), \operatorname{Pt}(110), \operatorname{Pt}(111)$ with $n=200-500, \operatorname{Pt}(554)$ with $n=10$, and $\operatorname{Pt}(553)$ with $n=5$.

Because methanol and formaldehyde produce similar molecular mass fractions in the mass spectrometer, the soluble intermediates in the direct pathway cannot be detected directly in the OLEMS experiments. This problem was circumvented by measuring methylformate, which is formed in the reaction between methanol and formic acid. However, since it is reported that formaldehyde can be 
formed in significant yields during the electrochemical oxidation of methanol [41, 42], methylformate can be used only as an indicator for the direct pathway if formic acid is formed in the same pathway as formaldehyde. Since formaldehyde is almost completely hydrolyzed to methylene glycol $\left(\mathrm{H}_{2} \mathrm{C}(\mathrm{OH})_{2}\right)$ in aqueous solutions [43], which can be oxidized to formic acid on the Pt surface [44], a reaction path producing formaldehyde indeed implies the existence of formic acid in solution, making the detection of methylformate a practical method for measuring the activity of the direct pathway in methanol oxidation. Therefore, the relationship between the electrode surface structure and the activity of the direct and indirect pathways was obtained by following the ratio between the masses of methylformate $(\mathrm{m} / \mathrm{z} 60)$, indicating the activity of the direct pathway, and $\mathrm{CO}_{2}(\mathrm{~m} / \mathrm{z} 44)$, a measure of the activity of both the indirect pathway and the direct pathway. Consequently, a higher $m / z$ 60:44 ratio points to a higher selectivity towards the direct methanol oxidation pathway.

On the basal planes, the cyclic voltammograms show that the maximum activity toward the electrochemical oxidation of methanol decreases in the order $\operatorname{Pt}(100)>$ $\operatorname{Pt}(110)>\operatorname{Pt}(111)$ both in sulfuric acid and in perchloric acid. As an example, a typical mass resolved voltammogram obtained from the OLEMS experiments for $\mathrm{Pt}(100)$ is shown in Fig. 7. The methylformate- $\mathrm{CO}_{2}$ ratio signals integrated over a single voltammetric cycle in sulfuric acid are 3.3, 2.4, and 1.2 for $\operatorname{Pt}(111), \operatorname{Pt}(110)$, and $\operatorname{Pt}(100)$, respectively (see Table 1), indicating that, in this medium, the selectivity towards the direct methanol oxidation pathway of a Pt basal plane is negatively correlated with its overall activity. A noticeably different trend in the $\mathrm{m} / \mathrm{z}$ 60:44 ratio is observed for the cyclic voltammograms recorded in perchloric acid: compared to sulfuric acid, the selectivity of $\operatorname{Pt}(100)$ and especially $\operatorname{Pt}(110)$ towards the direct oxidation pathway is enhanced, while $\operatorname{Pt}(111)$ is less active towards the direct pathway in perchloric acid compared to that in sulfuric acid. This observation is in agreement with results from Batista et al. [45], who found that on $\mathrm{Pt}(111)$ the pathway producing adsorbed $\mathrm{CO}$ is inhibited in the presence of $\mathrm{H}_{2} \mathrm{SO}_{4}$. This enhanced selectivity of the direct oxidation pathway in sulfuric acid was explained as follows: adsorption of methanol via the $\mathrm{C}$-atom and subsequent dehydrogenation to $\mathrm{CO}_{\mathrm{ad}}$ requires several neighboring Pt sites, while adsorption of methanol as methoxy and subsequent dehydrogenation to formaldehyde requires only a single vacant surface site [40, 41]. A recent study by Cuesta has shown that on $\mathrm{Pt}(111)$ the ensemble required for $\mathrm{CO}_{\mathrm{ad}}$ formation must at least consist of three Pt atoms arranged in an equilateral triangle [46]. Since (bi)sulfate adsorbs much more strongly on $\mathrm{Pt}(111)$ than perchlorate, it is expected that the number of ensembles of vacant sites available for the formation of $\mathrm{CO}_{\mathrm{ad}}$ species, is much lower in sulfuric acid than in perchloric acid, effectively suppressing the indirect pathway in sulfuric acid on surfaces with a low number of crystalline defects.

To gain further insight in the structure sensitivity of the methanol oxidation reaction, the mass ratio 60:44 was followed as a function of the potential (Fig. 8). In sulfuric acid all recorded signals (Fig. 8a) show a similar trend: in the positive scan, starting from $\sim 0.6 \mathrm{~V}$ (versus RHE), poisoning $\mathrm{CO}$ is oxidized to $\mathrm{CO}_{2}$, resulting in a decrease in the 60:44 mass ratio on all surfaces. In the return scan, competitive adsorption between (bi)sulfate and methanol reduces the number of ensemble sites available for the indirect pathway, thereby increasing the 60:44 mass ratio. At potentials below $\sim 0.6 \mathrm{~V}$ (versus RHE), CO is stable on the surface. On the one hand, this leads to an increase in the 60:44 ratio, since at these potentials only methylformate (and small amounts of $\mathrm{CO}_{2}$ produced in the direct
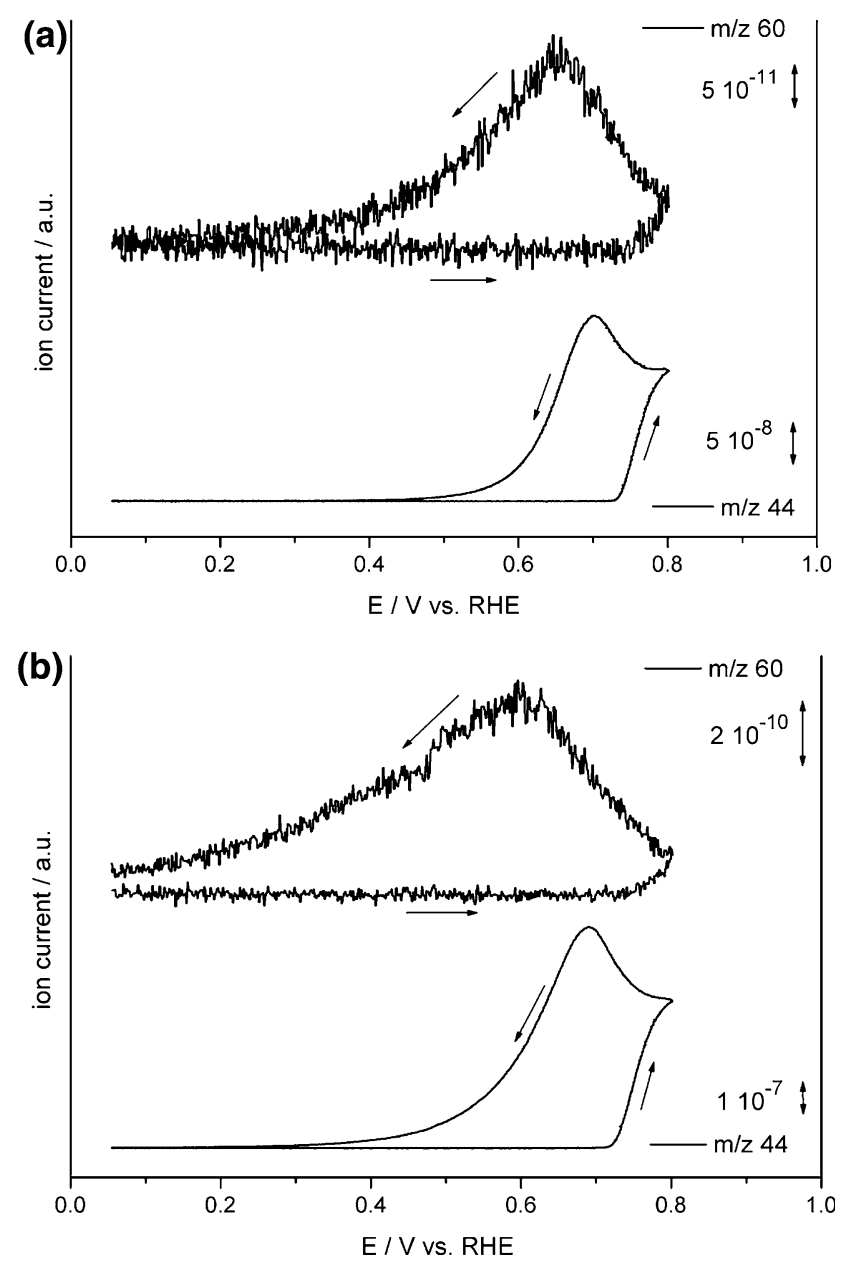

Fig. 7 Mass resolved cyclic voltammograms for $\mathrm{Pt}(100)$ in $0.5 \mathrm{M}$ methanol and (a) $0.5 \mathrm{M} \mathrm{H}_{2} \mathrm{SO}_{4}$ or (b) $0.5 \mathrm{M} \mathrm{HClO}_{4}$ at a scan rate of $2 \mathrm{mV} / \mathrm{s}$. The top mass shown displays the methylformate $(\mathrm{m} / \mathrm{z}, 60)$ signal and the bottom one the carbon dioxide $(\mathrm{m} / \mathrm{z}, 44)$ signal [40] 
Table 1 Ratio of methylformate $(\mathrm{m} / \mathrm{z}, 60)$ and $\mathrm{CO}_{2}(\mathrm{~m} / \mathrm{z}, 44)$ mass signals calculated for the oxidation of $0.5 \mathrm{M}$ methanol in $0.5 \mathrm{M}$ $\mathrm{H}_{2} \mathrm{SO}_{4}$ or $0.5 \mathrm{M} \mathrm{HClO}_{4}$ for $\mathrm{Pt}(111), \mathrm{Pt}(110), \mathrm{Pt}(100), \mathrm{Pt}(554)$, and $\mathrm{Pt}(553)$ integrated over one voltammetric cycle at $2 \mathrm{mV} / \mathrm{s}$

\begin{tabular}{lll}
\hline & Mass $60 / 40$ ratio $\times 10^{-3}$ & \\
\hline Surface & $\mathrm{H}_{2} \mathrm{SO}_{4}$ & $\mathrm{HClO}_{4}$ \\
$\operatorname{Pt}(111)$ & 3.3 & 1.5 \\
$\operatorname{Pt}(110)$ & 2.4 & 6.8 \\
$\operatorname{Pt}(100)$ & 1.2 & 1.7 \\
$\operatorname{Pt}(554)$ & 1.4 & 1.9 \\
$\operatorname{Pt}(553)$ & 1.8 & 3.1 \\
\hline
\end{tabular}

The given values are averages of 2-3 separate experiments. Reproduced from Ref. [40]
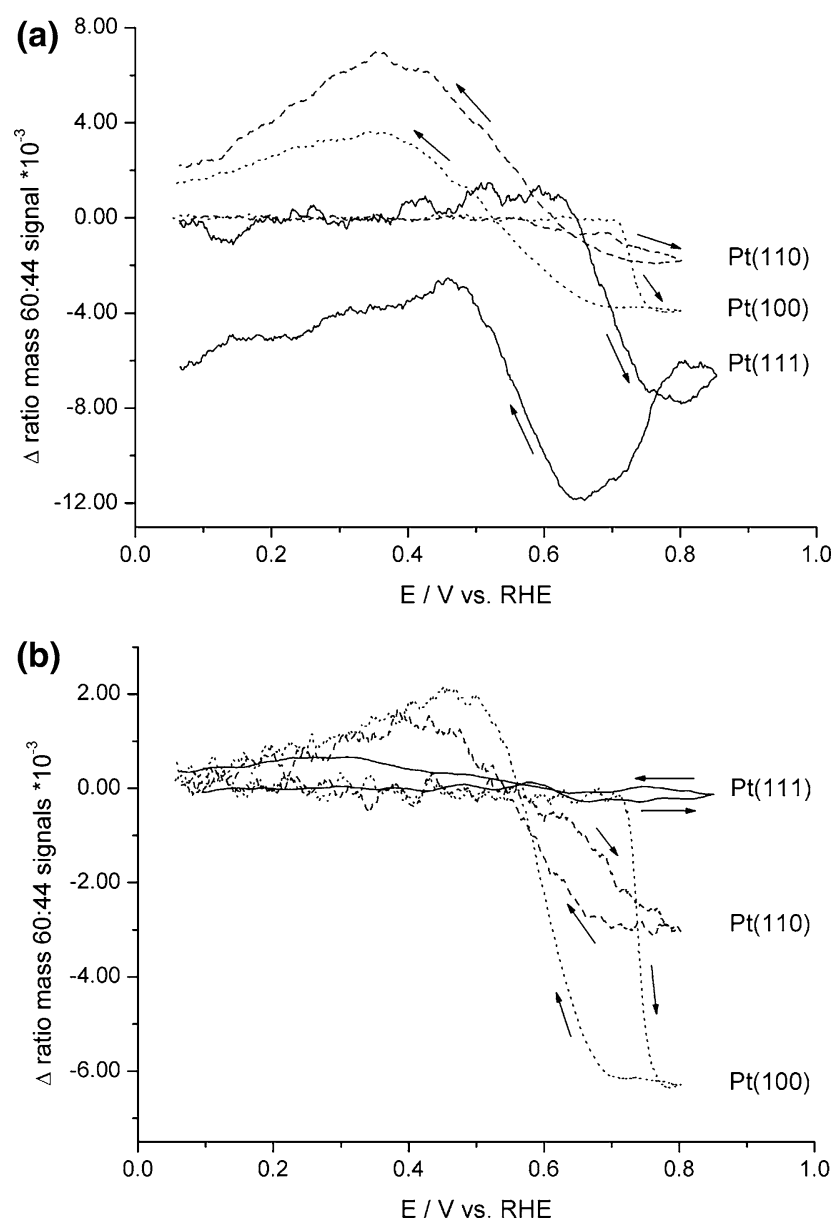

Fig. 8 Potential dependents plots of the $m / z$ 60:44 ratio measured for the oxidation of $0.5 \mathrm{M} \mathrm{MeOH}$ by cyclic voltammetry in (a) $0.5 \mathrm{M}$ $\mathrm{H}_{2} \mathrm{SO}_{4}$, or (b) $0.5 \mathrm{M} \mathrm{HClO}_{4}$ on $\mathrm{Pt}(111)$ (solid line), $\mathrm{Pt}(110)$ (dashed line), and Pt (100) (dotted line) at a scan rate of $2 \mathrm{mV} / \mathrm{s}$. The $\mathrm{m} / \mathrm{z}$ 60:44 ratios are displayed as deviations from ratio of the background levels detected by the mass spectrometer [40]

oxidation pathway) is detected. On the other hand, the stable $\mathrm{CO}_{\text {ads }}$ slowly poisons the surface, blocking both pathways. These two effects lead to a maximum in the $\mathrm{m} / \mathrm{z}$
60:44 ratio at $\sim 0.45 \mathrm{~V}$ (versus $\mathrm{RHE}$ ) for $\mathrm{Pt}(100)$ and $\mathrm{Pt}(110)$. The maximum for the 60:44 mass ratio for $\mathrm{Pt}(111)$ is shifted to lower potentials due to (bi)sulfate desorbing from this surface at potentials lower than $0.45 \mathrm{~V}$. This leads to an increase in the number of sites available for methanol decomposition, forming either $\mathrm{CO}_{\mathrm{ad}}$, which is not detected in the OLEMS setup, or soluble intermediates, resulting in an increase in the $m / z, 60: 44$ ratio. The relative selectivity towards the direct pathway increases in the order $\operatorname{Pt}(100)<\operatorname{Pt}(110)<\operatorname{Pt}(111)$ (c.f. Table 1).

In perchloric acid (Fig. 8b), the trend is similar, although the relative selectivity towards the direct pathway changes to $\operatorname{Pt}(111)<\operatorname{Pt}(100)<\operatorname{Pt}(110)$. Again, the 60:44 mass ratio decreases at potentials above $0.6 \mathrm{~V}$ (versus RHE) in the positive scan due to oxidation of adsorbed CO and, in the negative scan, show a maximum due to the inability to oxidize $\mathrm{CO}_{\mathrm{ad}}$ below this potential. Despite the fact that $\operatorname{Pt}(111)$ and $\operatorname{Pt}(100)$ present similar calculated values in Table 1, the latter produces relatively more soluble intermediates at lower potentials than the former.

Based on results of a voltammetric and chronoamperometric study obtained on stepped platinum electrodes of $[n(111) \times(111)]$ orientation in sulfuric acid, augmented by fitting of the current-time curves with a mathematical model, it was concluded that the methanol oxidation reaction is strongly catalyzed by the presence of steps and defect sites [47]. Moreover, the current drop in the chronoamperometric transients was found to be faster on surfaces with a high step density, implying that surface poisoning by the decomposition of methanol into $\mathrm{CO}_{\mathrm{ad}}$ takes place preferentially at or near the steps of (110) orientation. The mass 60:44 ratios on these surfaces found in the OLEMS measurements are presented in Table 1 and show that not only the total reaction rate is enhanced by steps, but also the selectivity towards the formation of soluble intermediates in both electrolytes (with the notable exception of methanol oxidation on $\operatorname{Pt}(111)$ in sulfuric acid, as discussed above) [40].

By resolving the potential dependent mass signals (Fig. 9), a considerable difference was found between the potential dependent pathway selectivity in sulfuric and perchloric acid. In sulfuric acid, at potentials higher than $0.6 \mathrm{~V}$ (versus RHE), the $\mathrm{m} / \mathrm{z}$ 60:44 ratio decreases with increasing step density, indicating that in this potential region, the influence of the indirect oxidation pathway increases with step density. In the return scan, the selectivity towards the direct oxidation pathway increases in the order $\operatorname{Pt}(554)<\operatorname{Pt}(111)<\operatorname{Pt}(553)$. In perchloric acid media, the selectivity towards the direct pathway changes to $\operatorname{Pt}(111)<\operatorname{Pt}(554)<\operatorname{Pt}(553)$, i.e., the selectivity increases with increasing step density, illustrating the varying effects of anion adsorption on the oxidation at steps and terraces. On (111) terraces, the strongly 

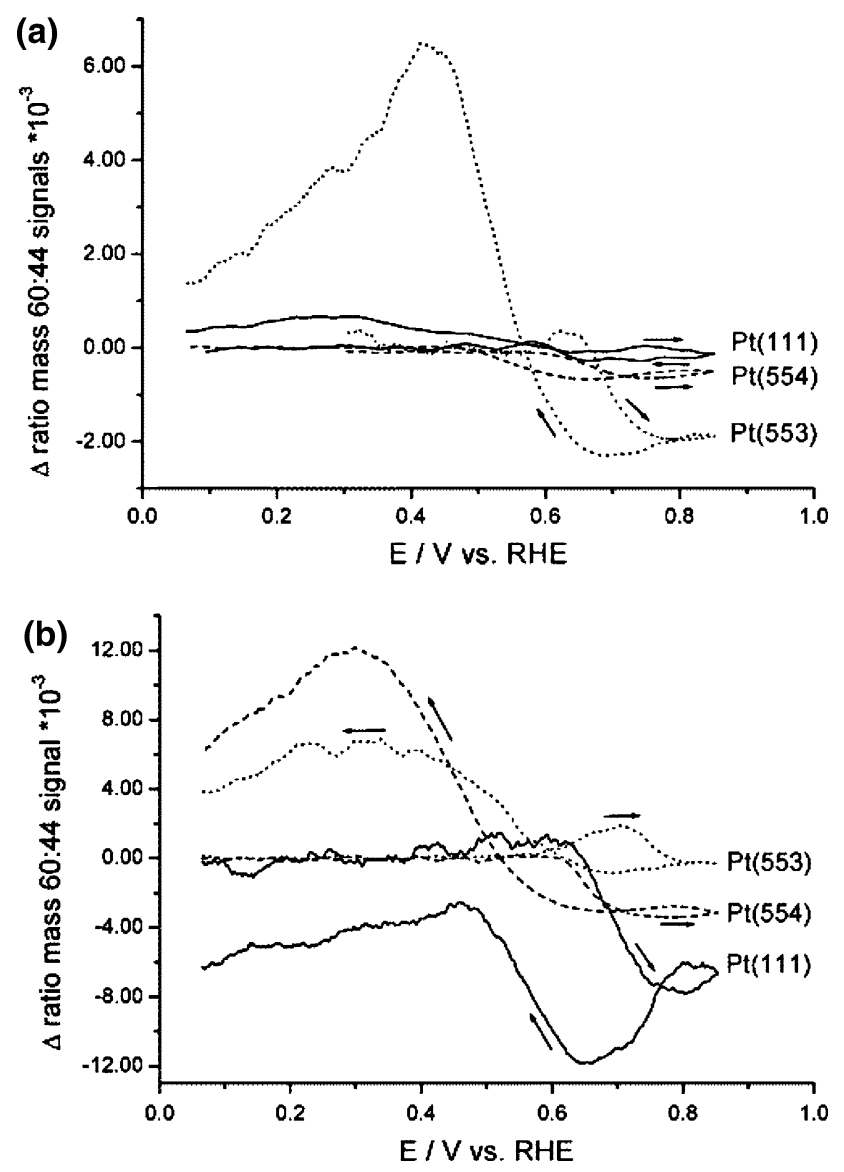

Fig. 9 Potential dependents plots of the $m / z$ 60:44 ratio measured for the oxidation of $0.5 \mathrm{M} \mathrm{MeOH}$ by cyclic voltammetry in (a) $0.5 \mathrm{M}$ $\mathrm{H}_{2} \mathrm{SO}_{4}$, or (b) $0.5 \mathrm{M} \mathrm{HClO}_{4}$ on $\mathrm{Pt}(111)$ (solid line), $\mathrm{Pt}(554)$ (dashed line), and Pt (553) (dotted line) at a scan rate of $2 \mathrm{mV} / \mathrm{s}$. The $\mathrm{m} / \mathrm{z}$ 60:44 ratios are displayed as deviations from ratio of the background levels detected by the mass spectrometer [40]

adsorbing (bi)sulfate inhibits the formation of $\mathrm{CO}_{\text {ads }}$ produced in the indirect pathway, while it suppresses the direct pathway on step sites compared to perchloric acid electrolyte. A possible explanation would be that (bi)sulfate hinders the approach of methanol to the steps, which by themselves catalyze the direct reaction pathway. Finally, it should be noted that although the selectivity towards the direct oxidation pathway is higher on $\operatorname{Pt}(110)$ than on $\operatorname{Pt}(554)$ and $\operatorname{Pt}(553)$, the total oxidation current densities for the stepped surfaces are higher. This may indicate that the oxidation of methanol via the indirect pathway producing $\mathrm{CO}_{\text {ads }}$ requires a combination of both steps and neighboring terrace sites, since in the absence of terraces, as on the $\operatorname{Pt}(110)$ surface, and in the absence of steps in sulfuric acid media, as on the $\operatorname{Pt}(111)$ plane, methanol preferably decomposes to soluble intermediates.

On basis of the literature data and the OLEMS data, a detailed and consistent reaction scheme incorporating both the direct and indirect pathway was suggested (Scheme 1).
As in the mechanism of Cao et al., the decision between the direct and indirect pathway is already made at the initial dehydrogenation step in the approach of the methanol to the surface [39]. The indirect path (reactions 1-7) is initiated by the dehydrogenation of methanol to hydroxymethyl, which is further dehydrogenated to a $\mathrm{C} / \mathrm{O} / \mathrm{H}$ species, the nature of which is still unclear, and eventually to $\mathrm{CO}_{\mathrm{ads}}$, which acts as a surface poison at low potentials. The OLEMS results indicate that the indirect pathway is favored on (111) terraces in the absence of a strongly adsorbing anions and on the $\mathrm{Pt}(100)$ plane. The direct pathway, reactions $8-15$, is initiated by $\mathrm{O}-\mathrm{H}$ scission to form methoxy, a reaction known to occur readily under UHV conditions [48]. Under electrochemical conditions, the OLEMS data suggest methoxy formation is preferred on $\mathrm{Pt}(111)$ in sulfuric acid media, on Pt surfaces with (110) steps in the absence of (bi-)sulfate and on $\mathrm{Pt}(110)$ regardless of the electrolyte. Furthermore, DFT calculations by Cao et al. indicate that dehydrogenation to methoxy is also preferred on (100) steps [39]. The formed methoxy is further dehydrogenated to adsorbed $\mathrm{H}_{2} \mathrm{CO}$ (reaction 9), which may desorb as formaldehyde. Formaldehyde is then nearly completely hydrated to methylene glycol, which will be oxidized to formic acid in solution, either directly (reaction 12) or through adsorbed formate (reaction 11 and 13). Finally, this scheme also explain the fact that formate was observed on platinum surfaces during the electrochemical oxidation of methanol (reactions 8-12), formic acid (reaction 13) and formaldehyde (reactions 10-13), as well as the fact that $\mathrm{CO}_{\mathrm{ads}}$ was found during the oxidation of formaldehyde and of formic acid (reactions 10, 11, and 16) by various authors [44, 49-51], substantiating the proposed reaction scheme.

\section{Conclusions}

In this paper, we have reviewed the electrochemical oxidation of carbon monoxide on stepped single-crystal platinum and rhodium surfaces, as well as the oxidation of methanol on single-crystal platinum electrodes. For the oxidation of carbon monoxide, a common poison in fuel cell catalysis, two processes can be distinguished on $\mathrm{Pt}[n(111) \times(111)]$ electrodes in sulfuric acid: a reaction initiation which shows an apparent zeroth-order dependence on the $\mathrm{CO}$ coverage, followed by the main oxidation process of the Langmuir-Hinshelwood type with competitive adsorption between $\mathrm{CO}$ and $\mathrm{OH}$. Both the reaction initiation and the main oxidation process are structure sensitive: with increasing step density, the current in the reaction initiation process increases, while the main oxidation process proceeds faster as well. The kinetics of the main oxidative process can be described by a mean field 
Scheme 1 Complete reaction scheme for the electrochemical oxidation of methanol on transition metal surfaces [40]

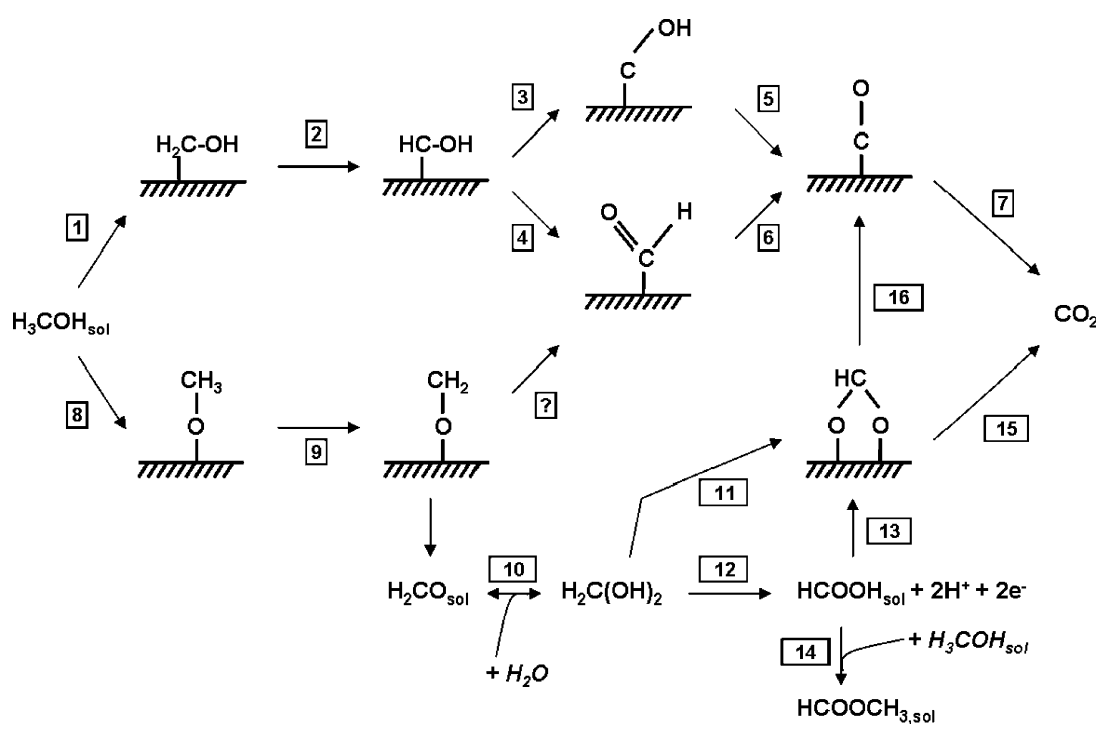

sulfuric acid, while the indirect pathway is favored in perchloric media. This was explained by assuming that certain ensemble sites are needed for $\mathrm{C}-\mathrm{H}$ bond scission which leads to the formation of $\mathrm{CO}_{\text {ads }}$. In sulfuric acid, due to the strongly adsorbing nature of (bi)sulfate, the amount of available ensemble sites is lower than in the presence of weakly adsorbing anions. The presence of steps of (110) orientation increases the total reaction rate of the methanol electrooxidation reaction and the selectivity towards the direct methanol oxidation pathway in sulfuric acid. However, the (maximum) activity for $\operatorname{Pt}(110)$ is lower than the activities of the stepped surfaces $\operatorname{Pt}(554)$ and $\operatorname{Pt}(553)$, indicating the optimal surface combination for methanol decomposition to consist of a step site plus a neighboring terrace site. In perchloric acid, increasing step density leads to an increase in the selectivity towards the direct oxidation pathway, illustrating the strong effects of anion adsorption at steps and terraces. Finally, based on literature and OLEMS data, a detailed scheme of the methanol oxidation mechanism was presented, incorporating a pathway producing $\mathrm{CO}_{\mathrm{ads}}$ and a pathway leading to the formation of soluble intermediates.

Although the surface-science approach discussed in this paper provides valuable insights into the fundamental understanding of fuel cell reactions, relating the catalytic activity of ideal single-crystals to the behavior of catalytic nanoparticles still provides a significant challenge. Although it was thought originally that surfaces with higher step densities would mimic smaller particles, the contrary was observed for particles in the nanometer range: while carbon monoxide and methanol oxidation activities increase with step density, they decrease with smaller particle size $[52,53]$. Furthermore, a great variance is observed in results from different groups. A recent study by Maillard et al. provides a tentative explanation [53]: the 
particle size effect is related to a size-dependent $\mathrm{CO}$ diffusion rate as well as to a size-dependent interaction between $\mathrm{CO}_{\mathrm{ads}}$ and $\mathrm{OH}_{\mathrm{ads}}$. On the other hand, Arenz et al. attribute the difference between single-crystals and nanoparticles to the fact that larger nanoparticles are inherently rougher, providing more defect sites for $\mathrm{CO}$ oxidation [52]. A third explanation is that smaller particles are easier to oxidize, resulting in a build-up of a non-reactive oxygen species blocking the active sites [54]. Furthermore, the differences between the different groups were partly explained by the variation in nanoparticles preparation and electrode pre-treatment. A current challenge is to obtain a precise and consistent view on the field of fuel cell catalysis on nanoparticles, which has to be resolved before a fundamental molecular-scale understanding of fuel cell catalysis can be claimed.

Acknowledgments The research described in this paper was supported financially by the Netherlands Organization for Scientific Research (NWO). We are much endebted to Prof. Juan Feliu and his group at the University of Alicante for the very fruitful collaborations.

\section{References}

1. Beden B, Lamy C, de Tacconi NR, Arvia AJ (1990) Electrochim Acta 35:691

2. Gilman S (1964) J Phys Chem 68:70

3. Santos E, Leiva EPM, Vielstich W (1991) Electrochim Acta 36:555

4. Herrero E, Feliu JM, Blais S, Radovic-Hrapovic Z, Jerkiewicz G (2000) Langmuir 16:4779

5. Masel RI (1996) Principles of adsorption and reaction on solid surfaces. John Wiley \& Sons, New York

6. Petukhov AV, Akemann W, Friedrich KA, Stimming U (1998) Surf Sci 404:182

7. Koper MTM, Jansen APJ, van Santen RA, Lukkien JJ, Hilbers PAJ (1998) J Chem Phys 109:6051

8. Koper MTM, Jansen APJ, Lukkien JJ (1999) Electrochim Acta 45:645

9. Lebedeva NP, Koper MTM, Herrero E, Feliu JM, van Santen RA (2000) J Electroanal Chem 487:37

10. Lebedeva NP, Koper MTM, Feliu JM, van Santen RA (2002) J Phys Chem B 106:12938

11. Lebedeva NP, Koper MTM, Feliu JM, van Santen RA (2002) J Electroanal Chem 524:242

12. Bergelin M, Herrero E, Feliu JM, Wasberg M (1999) J Electroanal Chem 467:74

13. Akemann W, Friedrich KA, Stimming U (2000) J Chem Phys 113:6864

14. Markovic NM, Grgur BN, Lucas CA, Ross PN (1999) J Phys Chem B 103:487

15. Lebedeva NP, Koper MTM, Feliu JM, van Santen RA (2000) Electrochem Commun 2:487

16. Palaikis L, Zurawski D, Hourani M, Wieckowski A (1988) Surf Sci 199:183
17. McCallum C, Pletcher D (1976) J Electroanal Chem 70:277

18. Petukhov AV (1997) Chem Phys Lett 277:539

19. Reutt-Robey JE, Doren DJ, Chabal YJ, Christman SB (1988) Phys Rev Lett 61:2778

20. Reutt-Robey JE, Chabal YJ, Doren DJ, Christman SB (1989) J Vac Sci Tech A 7:2227

21. Reutt-Robey JE, Doren DJ, Chabal YJ, Christman SB (1990) J Chem Phys 93:9113

22. Ma JW, Xiao XD, DiNardo NJ, Loy MMT (1998) Phys Rev B 58:4977

23. Seebauer EG, Allen CE (1995) Prog Surf Sci 49:265

24. Lebedeva NP, Rodes A, Feliu JM, Koper MTM, van Santen RA (2002) J Phys Chem B 106:9863

25. Hollins P (1992) Surf Sci Rep 16:51

26. Xu JZ, Henriksen P, Yates JT (1992) J Chem Phys 97:5250

27. Xu JZ, Yates JT (1993) J Chem Phys 99:725

28. Yates JT (1995) J. Vac Sci Tech A 13:1359

29. Hopstaken MJP, Niemantsverdriet JW (2000) J Chem Phys 113:5457

30. Housmans THM, Feliu JM, Koper MTM (2004) J Electroanal Chem 572:79

31. Housmans THM, Koper MTM (2005) J Electroanal Chem 575:39

32. Barth JV (2000) Surf Sci Rep 40:75

33. Seebauer EG, Kong ACF, Schmidt LD (1988) J Chem Phys 88:6597

34. Housmans THM, Koper MTM (2005) Electrochem Commun 7:581

35. Herrero E, Alvarez B, Feliu JM, Blais S, Radovic-Hrapovic Z, Jerkiewicz G (2004) J Electroanal Chem 567:139

36. Housmans THM, Hermse CGM, Koper MTM (2007) J Electroanal Chem 607:69

37. Parsons R, Vandernoot T (1988) J Electroanal Chem 257:9

38. Markovic NM, Ross PN (2002) Surf Sci Rep 45:121

39. Cao D, Lu GQ, Wieckowski A, Wasileski SA, Neurock M (2005) J Phys Chem B 109:11622

40. Housmans THM, Wonders AH, Koper MTM (2006) J Phys Chem B 110:10021

41. Batista EA, Malpass GRP, Motheo AJ, Iwasita T (2004) J Electroanal Chem 571:273

42. Childers CL, Huang HL, Korzeniewski C (1999) Langmuir $15: 786$

43. Guthrie JP (1975) Can J Chem-Rev Can Chim 53:898

44. Miki A, Ye S, Senzaki T, Osawa M (2004) J Electroanal Chem 563:23

45. Batista EA, Malpass GRP, Motheo AJ, Iwasita T (2003) Electrochem Commun 5:843

46. Cuesta A (2006) J Am Chem Soc 128:13332

47. Housmans THM, Koper MTM (2003) J Phys Chem B 107:8557

48. Kizhakevariam N, Stuve EM (1993) Surf Sci 286:246

49. Miki A, Ye S, Osawa M (2003) Chem Commun 14:1500

50. Chen YX, Miki A, Ye S, Sakai H, Osawa M (2003) J Am Chem Soc 125:3680

51. Olivi P, Bulhoes LOS, Leger JM, Hahn F, Beden B, Lamy C (1994) J Electroanal Chem 370:241

52. Arenz M, Mayrhofer KJJ, Stamenkovic V, Blizanac BB, Tomoyuki T, Ross PN, Markovic NM (2005) J Am Chem Soc 127:6819

53. Maillard F, Savinova ER, Stimming U (2007) J Electroanal Chem 599:221

54. Cant NW (1980) J Catal 62:173 